\title{
KNOWLEDGE, ETHICS AND CHOICES: THEORIZING THE FUNCTIONAL MATRIX OF LITERATURE AS A HUMANITIES DISCIPLINE
}

\author{
Bhumika Sharma \\ Central University of Rajasthan, India
}

\begin{abstract}
One may inaugurate the contemporary post-theory era with thinking beyond the theoretical aspects of literature. Or, in other words, it may facilitate a revision of literary theories in terms of exploring their functionality. But, a complex question involved here is, what may be its implications. How may it affect various disciplines especially the Humanities which are, unlike Sciences, deal with the abstract issues like truth, reality, ethicality, justice and many more like that? With these questions, the present paper endeavours to address- What is the nature of the knowledge created by humanities' disciplines like literature and how can it be used for renovating existing socio-political structures. Are the disciplines of humanities required to be more interactive with the sciences in the present technological age? Does such interaction give a more 'holistic' view of knowledge essential for creating a sustainable society? Comprehending the dialogic process of what it is and what it should be, the paper probes into the interactive epistemology of interdisciplinary knowledge. Since the disciplines of humanities like literature are directly linked to the behavioural pattern that is always subject to change, it explains their functionality in a game-theoric framework. A game-theoric model by virtue of its play with 'relativity' serves as an appropriate model to explore the functional possibilities of literature as an academic discipline. The knowledge produced in Humanities stream helps to understand the underlying 'relativity' of varied constituents of socio-cultural designs. With reference to the game-theoric account of well-known theorists like Lewis, Nash, Edna Ullmann-Margalit, the present paper highlights the role of speculation and anticipation in formulation of socio-cultural ethics and its strategic role in creating cultural choices. Perhaps, the functionality of literature lies in, understanding the mathematical equations of knowledge, ethics and cultural choices that work out institutional structures and generate systems. It pushes literary theories for being more equilibrium oriented and provide working strategies than merely becoming critical and assuming a perfectionist disposition.
\end{abstract}

Keywords: Knowledge; Functionality; Interactive Epistemology; Relativity; Game Theory; Socio-cultural Ethics; Strategies

\section{Beyond Theory: Literary Criticism in Row}

The wide ranging discourse on plethora of literary theories over the years has generated a number of critical schools with their set theoretical assumptions and defined positions and commitments. But, today one can observe an evolving self-reflexivity in various theoretical postulations engendered within the framework that shape them. Does it articulate a dissent from within the epistemological domain of literary 'theory'? Or it is a collateral impact of constant mulling over the problematic that a theoretical approach deals with but finds difficult to solve. Does it portend the high time to break literature free from its theoretical garb and make it more application oriented? Where does literature stand in the whole attempt to purge theory from its abstract nature and focus on its applied aspects? Does it manifest a desire to make literary text instrumental for the desired social 
and cultural change Or the present exhaustion with theory simply indicate a wide ranging boredom with the frequent perspectival shifts that leave a literary text just an unstable open ended discourse with no final say. With these questions at the centre, one may inaugurate a move towards post-theory era which advocates thinking beyond the theoretical aspect of the literature. Or, in other words, it may facilitate a revision of literary theories in terms of their substantiality to give concrete and tangible output finding the functional aspects of a literary text. But, a more complex question involved here is, what may be its implications. How may it affect the literature as a discipline of Humanities which is, unlike sciences, deal with the abstract issues like truth, aesthetics, reality, ethicality, justice and many more like that? Paul de man, in his essay "The Resistance to Theory" states:

For a method that cannot be made to suit the 'truth' of its object can only teach delusion...

These uncertainties are manifest in the hostility directed at theory in the name of ethical and aesthetic value, as well as in the recuperative attempts of theoreticians to reassert their own subservience to these values. (273)

Does literature need to find out its objectives in social context first before being placed at the high altar of aesthetic formulation? What are the fundamentals prescribed for being categorised as truly theoretical or purely practical? As de man further suggests:

The normative principles of such a literary ambiance are cultural and ideological rather than theoretical, oriented towards the integrity of a social and historical self rather than towards the impersonal consistency that theory requires (275).

What does Man endeavours to highlight in the above statement about his theoretical postulation? In the contemporary era of science and technology the disciplines of humanities and social sciences require being more scientific in nature or at least more productive in terms of its socio-cultural output. These disciplines are expected to seek solutions rather than being obsessed with the rolling critical intent involved in the formulation of mere theories. The pressing demand on theory, especially in the discipline of humanities in general and literature in particular is, to prove its validity and talk about its applied consequences in the contemporary post-modernist world. It requires an introspective visit to the functional aspects of literature for finding out the answers.

\section{Interactive Epistemology of Knowledge: Science and Humanities}

What are the possible dimensions of literary functionality is a long cherished subject of critical deliberation right from Aristotle to Dryden and Pope, further from $19^{\text {th }}$ century critic Matthew Arnold to $20^{\text {th }}$ century Frankfurt school of criticism. Literature is generally associated with its cognitive, emotional, aesthetic, and ethical impressions that it is capable to produce.Some times it is viewed existing with the objectivesto amuse and instructwhereas on the other hand, it is found as a close ally of capitalism. Knowledge has always been a chief concern as well as an endless pursuit in this regard. But, knowledge is dynamic in nature. Along with the growth of academics as an institution, knowledge is defined, categorised, privileged and politicised as per the spirit of time. With a concern to comprehend the dialogic process of what it is and what it should be, there has been an intent probing into its epistemological functions. Whatever the presumptions, no era can finally limit knowledge into one single disciplinary dominion. Having acknowledged the malleability of knowledge, one may wonder what constitutes the intellectual element of knowledge as a source of information. What has been the rational perception of knowledge while seen as a canon established over the years. Moreover, how is it created? Is it collective or fragmented? What has been its transitional trajectory; linear or cyclic? The creation of knowledge itself has always been a crucial question to know about. 
After centuries of exploration, we have various academic disciplines demarcating the knowledge in terms of the defined areas of studies and its associated objects of intellectual enquiry. It resulted in the simultaneous development of a condescending approach, one discipline posing itself over the other in terms of knowledge. The long known scuffle between humanities and sciences to allege the true nature of knowledge and its efficacy is one of its examples. Each discipline claimed the superiority of knowledge created in the respective disciplinary domain. In the words of Joe Moran:

Those in the sciences (still) tend to criticise humanities scholars for disregarding empirical methods and relying on subjective interpretations; those in the humanities attack scientists, in turn, for a misguided faith in the possibility of absolute objectivity, a narrow conception of useful knowledge and an unwillingness to interrogate the broader social, political and cultural implications of their work (Moran, 150).

According to him:

Many of these disagreements can be traced not only to the different scope and subject matter of the sciences and humanities but their contrasting assumptions about how the knowledge should actually be accumulated (Moran, 150).

But, it is a matter of epistemic investigation, how far the created disciplines could have remained isolated and justified in boasting of their self-reliance? To what extend the knowledge produced in multifarious fields could validate the respective claims of its completeness in absolute term? Even the most contrasting demarcation of science and humanities, which have always raised fierce debates over the different subject matters and divergent methodologies, could never uphold their respective exclusiveness. Has either of them ever succeeded in proving its validity without being leaned on other for its implicational justifications? It is a matter of critical estimate. The unabated pace of civilisation moving from its primitive natural state to industrial capitalistic mode has proved the disciplinary interdependence bringing both the theory and praxis into one ambit of knowledge. Over the years, on the one hand, scientific theories became applicable in terms of meeting the demands of humankind; whereas, on the other hand humanities frequently embraced scientific methods to develop valid models to testify their socio-political and cultural outcome. Theses disciplinary boundaries could never compartmentalise either of the two or prevent an incessant epistemic percolation of knowledge at both sides.

Knowledge has proved borderless travelling from one sphere to other structuring and restructuring disciplinary boundaries and constructing the edificial paradigms either to believe in or to reject or may be to further rectify the constructed models at various historical stages. Celebrating a rich and variegated legacy of knowledge, if perceived from the lens of literary and cultural theories, the present post-modernist world stands closer to an interdisciplinary understanding of knowledge. It is marked with an accommodative epistemic tolerance, yet it still needs to move further to erase the selfenclosed categorisation. In the endless addition of 'post', 'post-post', 'post-post-post' phases of theories, the process of knowledge production somewhere is translated into the recurring shifts from empirical objectivity to inventive subjectivity and vice versa. But, in fact, the creation of knowledge can never be affixed with the abstraction of theory or factuality of empiricism. To put into Aijaz Ahmad's word:

Facts require explanations, and all explanations, even bad ones, presume a configuration of concepts, which we provisionally call 'theory'. In other words, theory is not simply a desirable but a necessary relation between facts and their explanations (Ahmad, 34).

In the contemporary epistemic structure too, a theoretical disposition does not 
afford its separation from the empirical testing, and at the same time, an empirical analysis too embrace the inferring summation into the form of theory? In Ernesto Laclau words:

What we have, instead, is a process of mutual contamination between 'theory' and 'empiria'the former having abandoned its aspirations to constitute a 'superhard transcendality' and the latter having lost the innocence associated with pure 'data' (Post Theory, "Preface", vii).

In the contemporary cultural format, the academic disciplines seem to stand at a point where universal generalisations dissolve into contextual sensitivity and contexts appear paving the way to identify the unmitigated patterns of generalisation. It is time for the literary theory to imbibe this interactive epistemology and review the analytical mode of literature in its new functional dimensionality. Contemporary academics need to understand the common body of knowledge that could decipher ontological and epistemological meaning without rigid disciplinary presumptions. In view of the world for being existed in relative terms; the academics cannot seek answers in isolation. It is a strategic orientation which literature, especially as a disciplinary practice in the realm of literary criticism, needs to take before being lost in the overwhelming noise of selfvalidation or refutation as an authentic source of knowledge.

\section{Coding the Behavioural Interplay: That's How Literature Works}

"How does literature work?" it is an oft-posed query while talking about the functionality of literature. Indeed, literature does not and, of course, cannot work as science through applied research whittling industrial output. The disciplines of humanities and social sciences are directly linked to the behavioural pattern that is always subject to change. It attends to the issue, why does a literary text, especially in the domain of humanities, fail to give an absolute solution or quantifiable output in terms of its functionality. The nature of a literary text is always distinct depending upon its emotional and ideological underpinning. It may be neoclassical, romantic, structuralist, feminist, postcolonial, deconstructive in character but in each case it encodes the behavioural interplay and postulates set objectives from a specific socio-cultural or aesthetic position. Many critics have strongly criticized the discursive nature of literary and cultural discourses for being merely theoretical. In their view, the rumbling nature of the critical discourses does not lead to clarity but ambiguity that moves them away from practical application. Does it mean a complete failure of literature or literary and cultural theories at the level of praxis? Or it portends to a sensitive slit that needs to be identified and addressed as well as fixed more cautiously than ever before.

If science stands as 'value free' and humanities as 'value bound' knowledge that affects their functional efficacy, it is urgently required to understand the working of both in the game-theoric framework. In this regard, both the disciplines produce knowledge as the study of 'relativity' and hence, stand, if not with the same intensity, vulnerable to the 'value' imposition. Although the discipline of humanities remains more precarious in comparison to science, yet it never closes its opportunity to be more logical and practical. In the words of Gregory Derry as posted in Chapter 7, "Thinking straight: Evidence, Reason, and Critical Evaluation" of his book What Science is and How It Works:

When issues turn on differences in values, faith, cultural background, and so on, then we are obligated to isolate these differences and identify them clearly. Differing values are no excuse for bad logic and lack of evidence. Valid argumentation in the murky and ambiguous issues of human affairs is not essentially different from valid argumentation in the esoteric realms of science; it is just more difficult. (Derry, 90)

Responding to various accusations generally laid upon on the ground of 'differences in value', Derry, inadvertently, evinces a possibility that brings science and humanities 
almost on equal ground. It brings into account the inevitable conception of 'relativity' which underlies every creation irrespective of its ontological or epistemological nature. Perceiving the nature of a 'creation' as an ever evolving design, it becomes a disciplinary imperative to understand the game of 'relativity' not simply at the level of atoms and molecules or energy principles as done in the sciences but also in terms of human behaviour that constitute the subject matter of humanities and social sciences. Literature as a discipline helps to read the underlying relativity in terms of human relations at individual as well as at the level of groups, class, and cultures. 'Relativity' defines the interrelationship of constituents in every design, whether animate or inanimate, subjective or objective, theoretical or practical, contextual or context free. It is just the matter of; how perfectly a literary text can comprehend the underlying mathematics of relativity before formulating its various propositions in its disciplinary domain. It is also to be discerned what parameters it would set to address the volatility attributed to the unavoidable 'relativity' involved in the structural designs of behavioural interplay. Literature as a discipline of humanities not only focuses on 'humanity' but also expands its scope with regard to ecology and cosmic schema?

Concerning with the 'life experiences' as the subject matter of literatures, these interconnections, while placed in a game-theoric framework, view the life from the lens of ethicality especially with regard to specific socio-cultural contexts. It brings out the unending game of speculations. It may lead to various strategic decisions, which are examined in their holistic implications before being promulgated as a theoretical stand for further practical implications. Humanities and sciences go hand-in-hand. The contemporary cultural crux necessitates this idea to function both at the levels of theory and praxis. Is it a new 'development' or just 'old wine in new bottle'? How can it be comprehended in present academic design? Would a game-theoric view of 'interdisciplinary relativity' explain it? Does it portend the new academic orientation towards a concept of 'holistic' knowledge? Is it perceivable? Let's understand the whole notion with the help of a case study in Indian context. An innovative measure in recent years in Indian educational system has ensued the increasing importance and deliberate inclusion of humanities courses in the institutions of science. For instance in an article appeared in Times of India the author refers to the study made on the recent developments in the academic curriculum in Indian IITs (Indian Institutes of Technology). It states:

But over the last decade, at several of the IITs, the HSS (humanities and social sciences) schools have junked their 'service-course department' status -- equipping hardcore techies with a smattering of culture - and running $\mathrm{PhD}$ programmes.

The published study includes the case of several Indian IITs including IIT, Delhi, IIT, Mumbai, IIT Madras, and others like the newly founded one in Gandhinagar. The article quotes the views of faculty and students over the recent trend of interdisciplinary undertakings and increasing intervention of humanities in the established institutes of sciences. While interviewed, Bhaskar Ramamurthi, Director, IIT Madras, stated that humanities students "bring a different flavour to activities outside of class, to the institute's literary and theatrical activities."On the other hand, Yashasvini Rajeshwar, in her fourth-year of development studies at Madras, said "Our ways of thinking are moulded differently and our problem solving approaches probably vary. But at the root of it, when we are handing out, we cease to be the Arts major and the engineers and become friends just like any other group of 20-something year-old."Similarly, giving a glimpse of new set-ups like IIT, Gandhinagar, which is established in 2008, the study further reveals: 
Here, $20 \%-25 \%$ of the courses BTechs take are, in the liberal arts and the type of content is different. There are courses in Urdu poetry - 75 students took that - and in classical Indian music," says Achal Mehra from the department of humanities. The Safety Centre (particularly the behavioural safety section) and Archaeological Sciences Centre too use inputs from the humanities departments.

How should one view such novel drifts in academic discipline? What do these new models of knowledge production suggest? Is it a move towards holistic knowledge, required for the realisation of much proclaimed motto of 'sustainable' development with its triumvirate structure of ecological, economic and cultural sustainability? How could these novel academic trends be explained at the level of theory? What could be the future orientation of these new educational formats? Would such intended holistic knowledge help to better explain the prerequisites of obligatory policy imperatives that affect the overall socio-cultural system and its institutions? Where do humanities in general and literature in particular stand in this regard?

These are the questions subject to deep probing and intense investigation. Perhaps, they may be better understood through the game theory models that explain the relation of knowledge with multiple choices which the canon knowledge always opens. A sustainable society needs to decipher this functional matrix of knowledge, ethics and choices in the act of decision making and find out how it works in case of literature as a cultural agency. A literary text reveals the nuances of socio-cultural systems and its impact on various individual/groups' behavioural interplay. With reference to the game-theoric account of well-known theorists like Lewis, Nash, Edna Ullmann-Margalit, one may see the role of speculation and anticipation in formulation of socio-cultural realities. Here lies the role of literature in the era of science since as a discipline of humanities it addresses those speculation and anticipation and imparts the much required complementary 'knowledge' and managerial 'ethics' that the level-headed streams of science may lack.

\section{Modelling Multiple Choices: A Game-theoric Account}

Much famous and widely appropriated, 'Game theory' as a mathematical model somewhere suggests the need to think in terms of interactive epistemology: What it means for a collective to have common beliefs or knowledge, and what are the consequences of this knowledge for the social outcomes resulting from agents' interactions. Many philosophers like Bicchieri (1989), Skyrms (1990), and Stalnaker (1999) worked in this area to understand the mathematics underlying the social practices and cultural norms.But before undertaking the review of their models, first begin with the elementary understanding of a game-theoric framework. While explaining the theory of Nash equilibrium in his book An Introduction to Game Theory, Martin J. Osborne defines a strategic game as "a model of interacting decision makers." It consists of "a set of players, a set of actions for each player and preferences over the set of actions profile for each player" (11) Replicating the model in socio-cultural contexts, we have the groups or communities as social players of various strategic games at collective level. These games are designed to capture fundamental conflicts present in a variety of situations where an action may be called a strategy. The game is important not because one is interested in understanding the pay offs or incentives for the players for their choice of action but because many other situations have similar structures. While extended to understand the coordination-conflict situations of socio-political nature, it reckons the mathematics underlying various socio-cultural codes and its resultant normative modes. A game is designed to expound the 'relativity' 
involved in the construction of a socio-cultural matrix. There are two key concepts which help to explicate the structural design of any strategic game. First is contractual nature of 'relativity' that always perceives a negotiating approach among the players to safeguard the interests of all. The second component is the utilitarian principle which determines the incentives for players for their choice of certain strategic move.

Since each player is aware of the possible harm and uncertainty involved in the game, one prefers to explore rational choices to uphold collective common interest. At socio-cultural level, these choices can be designated by any name such as morality, ethics, law or may be any other nomenclature depending upon the type and intensity of the force associated with. As per the first principle, i. e., the contractual nature of 'relativity' morality consists of a set of rules that individuals voluntarily agree to abide by. It resembles the signing of a contract which covers the interests of those who accept its terms. Even the interests of those, who lack the ability to understand it and cannot sign, are protected by those who are in position to sign it. It is the game of coordination that generates ethics in the form of common belief and common move. To quote Tom Regan:

According to crude contractarian position, morality consists of rules that people agree to abide by. These are the people who have the power to enforce the rules that are drawn up in the contract.. Now it requires the purgation of the contractors of their bias or prejudices to extend the sense of justice even to those who are not the part of contract signatories. (Regan, 14)

The conception of ethics is an amalgamation of the direct and indirect duties to each other for being connected through an undeniable bond of 'relativity'. It works out the ethical principles on humanitarian ground. It is to ensure the humanitarian idea of justice at rational level. As cited by John Rawls in his well known work $A$ Theory of Justice, the theory of justice is set forth as a version of contractarianism. It endorses a move from personal to common or, in other words, from subjective to objective. It forces the involved parties to ignore the accidental features of being a human being- for example, white or black, male or female, a genius or modest intellect, since only by ignoring these differentiating features, as Rawls believes, we can ensure the underlying principles of justice in the contractarianism. A judicious approach makes a contract free from bias or prejudices.

Let's bring forth the other important criterion for the judgement of social ethicality- the 'utilitarian' principle. A utilitarian concept involves two moral principles. The first is 'equality' and the other 'utility'. The professed egalitarianism as the first objective counts everyone's interest with same weightage, whereas the second notion of 'utility' tries to work out the best balance between satisfaction and frustration for everyone affected by the outcome. Since in the two-person zero-sum game one person's gains exactly equal the net losses of the other, it becomes crucial to determine the point of equilibrium which could do justice to both the parties. The utilitarian principles of social ethics justify the moral code on the ground of the final product of the utilities. Some popular illustrations of game theory like the Prisoner's dilemma represent an apparent conflict between the morality and self-interest.

The game-theoric version of social relations throws light on the conflict-coordination bond of 'relativity'. It explains why 'conflict' is an underlying reality which could not be denied of, in any bilateral or multilateral social relationship but how, at the same time, it makes cooperation a prerequisite to preserve self-interest. Literature presents the sum game of 'life' in its portrayal of life's loss and gain from different perspectives. It does not come out simply as a portrayal of life dilemmas in narrative mode but also as 
strong ideological commitments of the author/text. They propose the creative theoretical postulations. The wide spectrum of literature consists of multiple models of individual and collective behavioural patterns suggesting the possibilities of innumerable choices and the game of conflict-coordination in socio-cultural decision making.

\section{Humanities and Mathematical Reasoning}

It is still convenient to view the knowledge produced by humanities in a game theoric framework but one may wonder how far this knowledge could be subjected to mathematical reasoning for socio-political decision making. Following the modern game theory as propounded by John von Neumann, which began with the idea regarding the existence of mixed-strategy equilibria, a socio-cultural ethical code can chooses the option which is most likely to bring about the balance of totalled satisfactions over totalled frustrations in a specific socio-cultural context. It may be infused with a totalitarian apprehension. But it is what the mathematical approach of the game theory tries to undo. Understanding the mathematics of ethics through literary texts as well as theory is to purge the decision making of its totalitarian element. A totalitarian norm is always answerable to the cultural forces for its corrupt intensions. It makes them liable and context sensitive with a counsel for more precautions. Its aggregative nature demands a cautionary move to ascertain an amount of flexibility and accommodation at collective level. The application of literary studies lies in comprehending the mathematics of ethics. It can be reckoned through the accurate calculation of aggregate utilitarian output within the contractarian framework of cultural formulations.

Now, the socio-political question interlaced in such design is how to designate the correct cultural agency for working out the mathematics of ethics. Who or which agency is authorised to lay down and execute a 'contract' and work out the aggregate result of positive and negative values of 'utilities'? What could be the appropriate criteria to judge the religious or secular, egalitarian or concessional element of such designated agency? Does it evoke the same power-contest among various socio-political and cultural institutions? Are all attempts to work out the correct mathematics of ethics, bound to end with corrupt power politics? The nature of the question, no doubt, makes it political yet, one may accept the fact that a game, on account of its strategic nature, is always bound to be political at certain level. Yet, still maintaining the impersonality of the game itself, if not of the players involved, one may state; it is precisely the study of power equations that facilitates a constructive cultural discourse. Since these propositions enable a host of dictums to serve as obligatory norms over given time span, by identifying the socio-cultural conditions with the structural design of the strategic games, somewhere, one may trace the foci of equipoise. It acknowledges, despite the integral conflicts, the possibility of a point of equilibrium, howsoever short lived and unstable, yet capable to suggest a strategic action to maximise the pay off in the given situation. A sustainable socio-cultural community always endeavours to attain that point of balance. It is the same point that has a potential of being adapted into a common belief or well accepted judicious law. It is innocent in its constitution till the time the players keeps it detached from the differentiating features what Rawls excerpts in his book Theory of Justice. But, indubitably, its vulnerability to corruption always keeps it in flux subjected to the whims and antics of power. It generates a structural susceptibility. In fact, it is always the disruption of the strategic point of equilibrium, which prop up rigid power structures and its associated exploitative practices. 
To bring out the ideological play that underlies the game-theoric models in humanities, one may draw attention to Althusser's concept of political and cultural hegemony. Althusser's conception throws light on the duality of forces which nurture various socio-political ideologies and their schematic execution in socio-political structures. Manipulation of ideologies results in the structuring of non-innocent games. Althusser's conception of ideology presents it as an 'unconscious', He describes it as a system, with its own logic and rigour, of representations, which is executed in the 'lived' relation between men and the world. But these ideologies are incapable to remain static. In the words of Althusser:

If, as Marx said, history is a perpetual transformation of men's conditions of existence, and if this is equally true of socialist society, then men must be ceaselessly transformed so as to adapt them to these conditions: if this 'adaptation' cannot be left to spontaneity but must be constantly assumed, dominated, controlled, it is in ideology that this demand is expressed... (Althusser, 235)

Hence the birth of every new ideology is a strategic move to be played in the power game. It is the ideological clash that strives to transmute the game structure. In fact, each socio-cultural change indicates the revision of the matrix of game to formulate novel ethical and moral norms which will be the new rules for the game to be further continued. Whether it is a drift from colonial imperialism to postcolonial resistance or from patriarchal set up and heterosexual societies to gender equity and LGBT rights, the power structures are made to mould for strategic restructuring. The mathematical tangency of the gametheoric account prerequisites the separation of the political content of ideology from the apolitical structural framework of any cultural design. The mathematics of ethics does not allow space for political corruption while formulating the common belief or a judicious cultural norm.

Following the mathematical construct of the game theory, one can examine the Nash equilibria from a nonaligned perspective to understand its humanist strain. Nash equilibria help to understand how a game-theoric model functions. It emphasises on two essential components. First, the players of apolitical game, given their beliefs about the other players' actions, always act in accordance with the theory of rational choice. Secondly, there is a common approval that these beliefs are correct. Precisely, Nash equilibria result from transforming a mixed-motive game into a coordination game. Its definition is designed to model a steady state among experienced players. While applied in the socio-cultural domain, what an adroit and judicious cultural agency is expected to do is to correctly comprehend the calculation of varied variables involved in the formulation of a socio-cultural matrix. In fact, a sustainable society emanates from the same principle of transforming the game of conflict into a coordination game. The notion of sustainability is expected to identify the points of socio-cultural equilibrium for being altered into legal and ethical code for ensuring cultural sustainability. Although expressed differently, yet following what Nash equilibrium embodies, it exhibits the quest for identifying stable 'socio-cultural' norms, which means if everyone else adheres to it, no individual wishes to deviate from it. In other words, it implies that all players' 'expectations are coordinated'.

Here what is important to note is that Nash Equilibrium does not in general correspond exactly to the idealised setting. Examples show that some games have a single equilibrium, others possess no equilibrium and many others may have many. Same is true with regard to diverse cultural contexts which have sundry possibility of equilibriums yet always remain in need of their being stabilised in one or the other form. But, whatever 
the context, a game-theoric view expects an analytical examination of human behaviour manifested in game. Its knowledge is essentially reliant on the profound understanding of 'relativity' and finding out how does it result in strategic decisions. Literature being the repository of human behavioural patterns always serves as a rich source for strategic decisions with regard to extant multiple choices in specific cultural contexts.

\section{Towards a Functional Theory of Literature}

Following Lewis' (1969) game-theoretic account of conventions, Edna Ullmann-Margalit (1977) and Bicchieri (2006) have developed theories of social norms. Ullmann-margalit relies on the apparatus developed by Schelling and Lewis to show that norms can be generated by coordination situation without the aid of explicit agreement among the parties involved. It indicates how the strategic moves in a game take shape of sociocultural practices and ethical traditions. It is the historical nature of socio-cultural practices that result in the invention of traditions. Although talking in architectural context, yet Christopher N. Matthews precisely quotes Eric Hobsbawn (1983) while recognising the parallel between the social practice and the invention of tradition. In his words:

...traditions require social practice, Hobson illustrates that we can observe both the origins and modifications of traditions by exploring and contextualising their actualisations over time... What was it about certain ways of doing things that made them traditional when they were in fact quite arbitrary and novel, and why would (and how could) something so timeless change? What is relevant here is that traditions, as they refer to a past, materialise cultural formations and modes of knowledge in a very specific way that allows their expression to go without critique. ("Preface", xi)

The socio-cultural norms transform into tradition as an outcome of allied game of relativity. Hence, the social ethics heavily depend on the structural design of the game played than anything else. So there is a need to understand the game, to identify its structure and render its mathematical modelling to find-out its socio-political significance. And, it is the function of literature to render the knowledge of common beliefs and possible strategic moves accessible to the various cultural agencies. The issues which remain relevant in this context are; May the game-theoric understanding of 'relativity' serve as the basis of the socio-political and cultural decision making theory. How precisely a cultural agency can calculate the cultural payoffs of socio-political ethics to design the other strategic game of contemporary relevance? The mathematical modelling of socio-cultural ethics may give the required theoretical knowledge for a more strategic understanding of diversified cultural praxis.

What it anticipates, especially in contemporary calculative technological age, is a need to understand the mathematical equations of social designs that work out institutional structures and generate systems. It is all about identifying the socio-cultural patterns and how do these patterns create and re-create traditions. What the discipline of humanities and social sciences need to examine is, both the political and apolitical aptness of those patterns which define specific socio-cultural behaviour. It is the mathematical understanding of cultural ethics that may work to sustain a society. The mathematical reasoning behind common beliefs and traditions not only explain the contractarian and utilitarian purpose of their constitution but also helps to resolve the dialectics of conflict and coordination in specific socio-cultural contexts.

Since it is high time for humanist disciplines like literature and literary theories to perform, rather than simply issuing fixated statements, the historical consciousness is 
expected to go hand in hand with the study of structural designs. It is important to trace the socio-cultural patterns and identify the trajectory of changing socio-political designs and the mathematical matrix behind it. Literature's engagement with the game-theoric view of relativity emphasises to explicate the cultural decision making. A humanist theory is never complete till it provides certain pragmatic tools to give strong and constructive policy frameworks. The present dilemma appears to push theory for being more equilibrium oriented and provide working strategies than merely becoming critical and assuming a perfectionist disposition. In Truth and the Ethics of Criticism, Christopher examines the way in which literary theory has redefined itself in a contemporary hermeneutic circle concerned with epistemological rigour and cultural critique. Norris argues that literary theorists can implement a series of correctives that may yet infuse the theoretical project with much needed doses of pragmatism and social relevance. Norris characterizes that paradigmatic shift as 'the retreat from high theory'(1), as an era in which 'a great deal depends on where one happens to be in terms of the wider socio-political culture and the local opportunities for linking theory and practice in a meaningful way." (5)

\section{References}

Ahmad, Aijaz. (2010). "Literature among the Signs of Our Time" In Theory: Classes, Nations, Literatures. New Delhi: Oxford University Press. 1-42

Althusser, Louis. (1977). For Marx. London: New left Books.

Bicchieri, C. (1989). Self Refuting Theories of Strategic Interaction: A Paradox of Common Knowledge. Erkenntnis, 30. 69-85

Chowdhury, Shreya Roy. "Service Departments' no more, Humanities, Social Sciences getting a leg up in IITs” Times of India. | TNN | Sep 26, 2014, 01.57 PM IST

http:/timesofindia.indiatimes.com/home/education/news/Service-Departments-no-more-Humanities-SocialSciences-getting-a-leg-up-in-IITs/articleshow/43515606.cms

Culler, Jonathan. (1997). Literary Theory: A Very Short Introduction. New York: OUP.

Derry, Gregory N. (2011). What Science is and How It Works. New Delhi: Overseas Press.

Laclau, Ernesto. (1999). "Preface" in Post Theory: New Direction in Criticism. Ed. Martin McQuillan, Graeme Macdonald, Robin Purves \& Stephen Thomson. Edinburgh: Edinburgh University Press.

Lewis, David. (1969). Convention: A Philosophical Study, Cambridge: Harvard University Press.

Man, Paul de. (2001). "The Resistance to Theory". Modern Literary Theory. Ed. Philip Rica \& Patricia Waugh. London: Hodder Arnold. (4th edition)

Matthews, Christopher N. (2002). An Archaeology of History and Tradition. New York: Kluwer Academic/ Plenum Publishers.

Moran, Joe. (2007). Interdisciplinarity. New York: Routledge.

Norris, Christopher. (1994). Truth and the Ethics of Criticism. New York: Manchester University Press.

Peterson, Linda H., John C. Brereton \& Joan E. Hartman. (2000). The Norton Reader. New York: W. W. Norton \& Company. (10 $0^{\text {th }}$ edition)

Rawls, John. (2005). A Theory of Justice. Cambridge: Harvard University Press.

Regan, Tom. (1985). "The Case for Animal Rights" In Defense of Animals. Ed. Peter Singer. New York: Basil Blackwell. 13-26.

Schelling, Thomas C. (1981). The Strategy of Conflict. Cambridge: Harvard University Press.

Skyrmas, Brian. (1990). The Dynamics of Rational Deliberation. Cambridge: Harvard University Press.

Stalnaker, Robert. (1999). Context and Content: Essays on Intentionality in Speech and Thought New York: Oxford University Press.

http://www.economics.utoronto.ca/osborne/igt/nash.pdf

The Emergence of Norms by Edna Ullmann-Margalit. Reviewed by: Adrian M. S. Piper. The Philosophical Review, Duke University Press. Article DOI: 10.2307/2185102. Stable URL: http://www.jstor.org/ stable/2185102 99-107.

Weatherson, Brian, "David Lewis", The Stanford Encyclopedia of Philosophy (Fall 2014 Edition), Edward N. Zalta (ed.),

$\mathrm{URL}=<\mathrm{http}: / /$ plato.stanford.edu/archives/fall2014/entries/david-lewis/ $>$. 